\title{
Correspondencia de José Gaos con J. Vasconcelos, O. Paz, León Felipe y L. Zea
}

\begin{abstract}
A vida de algunos hombres es el resumen de su tiempo. La $\mathcal{L}$ de José Gaos lo fue. Nadie como él representó mejor a aquel grupo de españoles que llegó a México en el malhadado año de 1939. Ante todo sobresalió como un hombre de ideas, pero también como crítico y político. Esto último era una consecuencia de lo primero. Siempre se mantuvo fiel - hasta las últimas consecuencias - a lo que pensaba, pero su capacidad crítica lo salvó del dogmatismo. Para muchos fue un maestro, es decir, un ejemplo.

Tomada del archivo personal de José Gaos, la correspondencia que Estudios publica en este número revela lo mejor del hombre y del intelectual: historiador de las ideas, crítico literario y político. Aunque escritas en distintas épocas todas las cartas - las suyas y las de Paz, Vasconcelos, León Felipe y Zea - nos dan un nítido retrato-autorretrato de un filósofo que es imprescindible en la historia del pensamiento en lengua española.
\end{abstract}


México, D.F., Oct. 4 de 1945

Sr. Dr. don José Gaos

Varsovia 35,

Ciudad.

Muy estimado y fino amigo:

Acabo de tener la grata sorpresa de hojear los dos ejemplares uno fino y otro ordinario que (sic) de su Antología del Pensamiento de la Lengua Española en la Edad Contemporánea, que ha tenido usted el acierto de componer y publicar.

Me dirigí enseguida, ¿por qué ocultarlo?, a las páginas que me están dedicadas. El acierto para la selección es tan grande que es casi seguro no hubiese salido distinta de haberla hecho yo mismo. Esto prueba su gran perspicacia de cazador de ideas.

Además quiero decirle cuánto me complace figurar en compañia de mentalidades tan eminentes como las que ha reunido en tan precioso volumen.

Le envío a usted en consecuencia, mi más rendido agradecimiento por la parte que quiso dedicarme y mi congratulación por la obra que realiza usted en la Antología de referencia, recogiendo cosas dispersas y otorgando decoro a un pensamiento que todavía en el orden internacional no suele ser muy estimado. En este sentido todos los de habla española le debemos reconocimiento.

Aprovecho la oportunidad para reiterarme como su Affmo. amigo y S. S. 
Octubre 22, 1945

Sr. Dn. José Gaos

Presente

Muy estimado y fino amigo:

A mi carta de hace unos días que no sé si por fin recibió, por lo que le adjunto la copia, y en la cual le daba las gracias por la Antología, quiero hoy añadir algunas palabras a su libro Pensamiento de Lengua Española y muy principalmente al capítulo que tuvo Usted la gentileza de dedicarme.

La fecha del capítulo que se refiere a mis trabajos es de 1940; en primer lugar siento no haberlo conocido sino hasta hace unos dias pues seguramente algunas observaciones suyas me hubieran ilustrado para alcanzar mayor claridad en la exposición de mi tesis contenida, si no es que repetida en mi reciente "Lógica Orgánica" pues en efecto los estudios de Ud. por inteligentes, imparciales y penetrantes, ilustran al autor sobre su propia doctrina, no sólo sobre las ajenas. No he tenido yo con frecuencia la suerte de que personas de categoría se ocuper, de mis escritos, de allí que me sean tan útiles comentarios como el suyo. Trabaja uno dentro de una oscuridad que sólo a ratos se alumbra y yo siento la necesidad de ayuda para penetrar en regiones que para mí son de descubrimiento de novedades a veces vírgenes y siempre de misterio.

Asi por ejemplo la teoría de la forma estética o la otra más reciente de mi Lógica Orgánica: el pensar una coordinación, no como dialéctica; y el problema de la coordinación de los heterogéneos, sin el artificio matemático lógico del denominador común y la abstracción; la tesis de lo impar, lo heterogéneo como condición de toda creación -doctrina que me parece opuesta a todo logicismo, matematicismo y que sin embargo aclara como si dijésemos la estructura misma del ser: todos estos problemas se me presentan como material virgen para la filosofía y en ellas he procurado ensayarme. ¿Por el método fenomenológico, dice Ud? No lo creo, aunque debo confesar que no acabo de entender el husserlismo que es como un poco de mi sistema de aprehensión de lo pensable. 
Por otra parte y fuera ya de lo filosófico debo confesarle ciertas complacencias y asentimientos que me provocan sus páginas como cuando atina Ud. en señalar al Dante como mi "amado maestro" y en efecto lo pongo por encima de las filosofías con pocas excepciones, Platón por ejemplo, o San Agustín, y ¿quién más? No sabría decirlo. En Dante hay superfilosofía porque hay teología pero no abstracta sino viva, positiva verdadera y total. Una cosmovisión que no (ha) sido superada todavía. En fin, el objeto principal de esta obra es presentarle mis agradecimientos más sinceros y repetirme con la más viva simpatía. Su amigo Affmo. y S. S.

José Vasconcelos

(rúbrica)

No he podido localizar la copia de mi primera carta pero el original debe estar en el "Fondo de Cultura"

México, D.F., a 28 de Octubre de 1945

Sr. D. José Vasconcelos

Presente

Maestro, he recibido sus dos cartas. Se las agradezco muy de veras. Viene $U$. en ellas a encontrar insólita una atención como la que me esfuerzo por prestar a la obra de los colegas: más insólita es aún que éstos la reciban y respondan en los términos en que $U$. lo hace.

Puede U. figurarse qué ufano me siento de haber acertado, por lo que se refiere a $U$., en el asunto, siempre tan espinoso, de la elección de textos. Igual que de que U. reconozca que entiendo y procuro practicar la crítica mucho más como un contribuir a potenciar valores que como insistir en las deficiencias patentes o un escudriñar en las veladas. Y también yo he aprendido siempre de la ajena, aún de la no concebida y practicada así, por lo que he recibido toda con cuanta permeabilidad me ha sido posible. En su segunda carta me hace U. indicaciones que no caerán en el vacío. 
Siga teniéndome por muy suyo, con admiración, agradecimiento y respetuoso afecto de

José Gaos

(rúbrica)

París, a 25 de Julio de 1961.

Sr. don José Gaos,

Torre de Humanidades, 2o. piso

Ciudad Universitaria,

México 20, D. F.

Querido y respetado amigo:

No había contestado a su carta porque esperaba, para hacerlo, que me llegase su libro. Lo recibí hace unos días y me lo leí de un tirón - cómo no había que leerlo. Pero esto le dará a usted una idea de mi interés. Aunque lo lei todo con gusto, hubo partes que me tocaron más de cerca: la primera, la novena, la décima (espléndida en todos sentidos) y el apéndice sobre el acto voluntario (un modelo).

Comprobé, una vez más, que no es usted tan difícil como dicen los perezosos. Además, lo que usted nos dice, aunque sea difícil, no está dicho de manera más difícil que la de ciertos novelistas jóvenes franceses (como Robbe-Grillet) y quizá nos concierne de manera más fundamental. Cierto (pero esto no es un reproche a la escritura sino una incitación al escritor), a veces se detiene usted precisamente cuando se piensa que ha llegado el momento decisivo, al instante de la confesión del acto (¿el pecado?) capital. Una y otra vez, sobre todo al final, nos deja solos, sueltos - como usted dice- cuando nos tenía literalmente suspensos. Se va a sus soledades pero ¿cree usted que nos deja en las nuestras? Quizá no estamos solos; quizá nuestro pecado, a la inversa de lo que ocurre con el fílósofo, no es la soberbia que segrega ni el hedonismo que disgrega, sino el resignado gregarismo. Sí, cada uno está solo, pero muy pocos tienen conciencia de que lo están y por eso no acaban de ser. 
Cada uno está sumergido, por decirlo así, en la soledad colectiva; el ánima desanimada, perdida en el anónimo. Creo que hoy todos necesitamos aprender a estar solos. Los solitarios aprenden a soportarse a sí mismos y después ya no les cuesta tanto trabajo soportar a los demás. La intolerancia moderna, el fanatismo, (del nacionalismo al comunismo) viene de que nadie quiere o puede estar a solas consigo mismo. Pero me desvío. Lo que quería decirle era que me hubiese gustado que su libro terminase con una descripción de la soledad del filósofo - por oposición y en oposición a la soledad anónima del hombre moderno. Es verdad que, como todas las grandes experiencias humanas, la experiencia de la soledad es incomunicable. ¿No es ésta, sin embargo, la misión de filósofos y poetas: comunicar lo incomunicable, decir lo indecible, pensar lo impensable?

Quizá mi reproche sea injusto. En cierto modo, el Análisis del acto voluntario nos enseña qué es lo que significa estar solo para el filósofo: algo radicalmente opuesto al sentimiento de soledad del mismo filósofo antes y después de su acto. Cuando piensa, a solas consigo mismo, el filósofo no se siente solo. Lo mismo le sucede al poeta, al amante y, dice usted, al maestro. De tanto sentirse a sí mismos ya no se sienten. En cambio, el hombre común, que nunca se piensa solo, que nunca está solo, se siente siempre solo aunque no lo sepa ni se dé cuenta de su soledad. No está solo: es solo. Basta con ver la cara de la gente en la calle o en los lugares públicos en que se congrega. Después de pensar, el filósofo vuelve a quedarse solo, como el poeta frente a su poema y el amante frente al cuerpo de su cómplice o de su víctima - deidad (el verdadero amor es o un crimen o un sacrificio y, sea lo uno o lo otro, algo consagrado). Ese momento dramático, admirablemente evocado al final de su libro, tras el episodio del "camión" JuárezLoreto (verdadero embrión de novela), merece otro capítulo. Mejor dicho: otro libro. En suma, sus "Confesiones Profesionales"(lo únicoque no me gusta es el título) piden una continuación, en la que nos diga, sin abandonar la reticencia (forma oblicua de la confesión pero al fin y al cabo confesión) lo que ahora no nos dice enteramente. Yo me atrevo a sugerirle que escriba usted una "novela" o, por lo menos, una "nouvelle"-es 
decir, un largo monólogo, a ratos dramático como en el episodio del "camión", otra meditación espiritual como en el análisis del acto voluntario, entrelazando las técnicas de la introspección y las de la escritura automática, la definición y la asociación de ideas. Algo así como un poema en prosa, entre Lucrecio y Beckett. Nos hace falta en español un texto así. ¿Atrévase!

Al comenzar esta carta pensé en comentar algunos de los temas que usted trata. Después de haber escrito los párrafos anteriores, me parece superfluo. Por no dejar, anoto al vuelo algunos puntos:

Si la Filosofía, como Metafísica o seudociencia de los objetos de la Religión, es ya arcaica, ¿qué es lo que va a substituirla? ¿Una nueva Religión? No la veo por ninguna parte. ¿Una nueva seudociencia de los objetos de la Metafísica (por ejemplo: el materialismo histórico)? Si la segunda posibilidad ya empieza a ser evidente, ¿no será ya tiempo de iniciar la crítica de la seudociencia de los objetos de la Metafísica? Por mi parte (pienso, sobre todo, en el materialismo histórico) vería esa crítica como algo análogo a lo que, precisamente, hizo Marx de la "ideología". Esta crítica sería, asimismo, una descripción del nihilismo como raíz de la credulidad contemporánea.

Afirmar que todas las filosofías son verdaderas ¿no equivale a decir que ninguna lo es'? Claro, decir esto es colocarse en el punto de vista de Dios o del Sujeto trascendental, pero ¿no es ese el único punto de vista realmente filosófico' La otra posibilidad es vertiginosa. Y hay más (o creo que hay más): el filósofo sólo puede afirmar que una filosofía es verdadera. Si afirma que ninguna lo es, esa afirmación es, ya, una filosofía, la única filosofía verdadera. Si afirma que todas lo son - aunque of rezcan visiones del universo inconciliables y mutuamente excluyentes, como efectivamente sucede - el filósofo niega la filosofía y se niega a sí mismo como filósofo. ¿No es ese el sentido último de Nietzche y Marx - ambos hablaron del "fin de la filosofía”? ¿No es esto su idea de la filosofía como biografía? Entonces... entonces reaparecen de nuevo la Religión y la Metafísica. Por lo visto, no hay manera de matarlas del todo ( $\mathrm{Y}$ Y si el grito terrible no fuese ¡Dios ha muerto! sino ¡Dios está vivo!...?) 
Nuestro historicismo significa, al fin de cuentas, que hemos perdido el punto de vista central (el punto de vista del Sujeto o de Dios). Pero no nos quedamos en el escepticismo ingenuo; vamos hacia adelante (o hacia dentro) e intentamos la filosofía de la filosofía, la poesía de la poesía. Quizá ésta sea nuestra última posibilidad de alcanzar la Filosofía y la Poesía verdaderas. A condición de que, en un momento dado de la meditación ( $\mathrm{y}$, para el poeta, de la creación), logremos asir lo que es lo mismo aunque no sea el mismo, quiero decir, el fundamento o la razón de ser; en ese momento la filosofía de la filosofía se vuelve Filosofía (a secas) y la poesía de la poesía, Poema. Pienso en Heidegger y en Mallarmé, que me parecen ser los que han ido más lejos por este camino. ¿Dos grandes fracasos? No sé. En todo caso, no menos grandes que los de Platón, Hegel, Dante, Blake. Y a propósito de Mallarmé, se me ocurrió, al escribir estas líneas, lo siguiente: los dados, lanzados por el Héroe fuera del espacio y el tiempo, caen en un aquí y un ahora relativos, es verdad; pero si leemos el poema al revés - como deberían leerse todos los grandes poemas-el ahora y el aquí relativos, los dados y el que los lanza, caen infinitamente, están cayendo... ¿Y en la nada o en el ser? No sé, pero siguen cayendo.

Vivir las filosofías de los otros, como vivir los poemas de los otros, es la manera moderna de crear y pensar, absolutamente original. No han hecho otra cosa Picasso, Joyce, Borges, Klee y, en fin, los más grandes. Copiamos las obras de la "cultura" como los antiguos copiaban las obras de la "naturaleza" y con los mismos sorprendentes resultados: la "copia" es una obra nueva y original. En cambio, los artistas que todavía dibujan o copian del natural, producen obras insignificantes y que se parecen a las del pasado.

$\mathrm{El}$ análisis del acto voluntario pide a gritos una segunda parte: el análisis de lo que lo llevó a analizar un acto voluntario -es decir, en última instancia, de lo que lo llevó a la Filosofía. (Por ahí podía empezar la "nouvelle" o poema en prosa que le propongo escribir). Análisis que no sería distinto, quizá, a la especulación sobre la Filosofía de la Filosofía, pero que sería más "biográfico" y más "fenomenológico" (la Filosofía descrita por dentro). Además, el análisis del acto voluntario no 
deja de tener analogía con el acto de escribir que también es lucha entre lo involuntario y lo voluntario, lo dado, lo que irrumpe, lo que distrae, etc. (Intenté algo parecido, pero sin rigor, en un capítulo de El Arco y la Lira: La Inspiración). Me parece que es un tema digno de ser meditado por usted... Y ya no sigo.

Créame que le agradezco de verdad su libro. Ya ve usted: me ha hecho - no diré que pensar pero, al menos, reflexionar.

Su amigo que lo admira

Octavio Paz (rúbrica)

De José Gaos a Octavio Paz

12 de Diciembre 1963

Esta carta es, antes que nada, para felicitarle, con gran satisfacción por el premio internacional de poesía. Antesala del Nóbel, preveo que el nuevo premio Nóbel de lengua española va a ser usted. En todo caso no debieran dárselo al poeta únicamente, sino conjuntamente al poeta y al prosista.

Creo haber ido leyendo todos sus libros de poesía o poco menos. Ultimamente leí Salamandra. Preferi particularmente, "Andando por la luz" y "Temporal", y "Apremio" "Palpar", "Rotación", “Agua y viento", "Ida y vuelta". Es una preferencia que puede delatar más mis alcances y limitaciones que la valía de las piezas para el deveras competente. En conjunto, su libro me ha dejado como me deja la poesía relativamente más reciente: perplejo. La verdad es que no la entiendo nada bien - en más de un sentido de "entender", estando muy dispuesto a conceder que la poesía no sea para entenderla, incluso en ninguno de los sentidos de "entender", o al menos primariamente para tal. Siempre he leído poesía, por lo que he leído bastante. Es el único género literario que he tenido tiempo - ratos - para leer durante largas temporadas, a veces de años; $y$ nunca he podido dejar de leer literatura, siquiera - isólo en el sentido que acabo de insinuar! - poesía. He leído también bastante sobre poesía. Por gusto por la crítica literaria latissimo-sensu y por interés profesional desde 
España hasta hoy ha venido siendo tema filosófico fundamental para mí el oír la expresión, para caracterizar lo filosófico por comparación con lo científico, lo religioso, lo literario... mas nada de ello ha sido suficiente para darme las entendederas que me faltan. En busca de una posible instrucción para entender más y mejor Salamandra - busca alentada, además, por el interés profesional a que acabo de referirme, he leído $E l$ arco y la lira. Y encontrando, bien pronto, más que el instrumento buscado, la confirmada explicación de mi déficit de inteligencia poética: "La soledad del poeta muestra el descenso social. La creación, siempre a la misma altura, acusa la baja de nivel histórico. De ahí que a veces nos parezcan más altos los poetas difíciles. Se trata de un error de perspectiva. No son más altos; simplemente, el mundo que los rodea es más bajo". De pleno acuerdo: no estoy a la altura de la poesia de mis días -postjuveniles. Descargar la "culpa" sobre la poesía misma me lo impidieron los escarmientos históricos. ¿No predijo Ortega en "Musicalia" que Debussy y Ravel no llegaron a tener nunca una popularidad como la de Beethoven o Wagner? Por haber cargado siempre, pues, con la "culpa" escribí antes confirmada explicación. En general, soy un rezagado de mí mismo; me he quedado, he quedado fijado en mis juvenilia, en todo: la última poesía que verdaderamente me gusta es la sombolista; la última novela, la del XIX hasta Proust inclusive; la última pintura, la impresionista...; en filosofía: ya el existencialismo no llegué a asimilármelo como la fenomenología.

Sólo que en El arco y la lira he encontrado muchísimo hasta más, pero muchísimo más, naturalmente. Hasta el punto de hacerme dudar de algo de que estaba convencido. Creía haber leído el libro al recibir el ejemplar que tuvo usted la amabilidad de dedicarme; pero me ha hecho dudar de ello lo que me ha sorprendido y tiene admirado en él -a menos que no se trate de juicios hechos en aquella lectura, que había olvidado haber hecho y acabo de rehacer como si fuesen nuevo. Claro, también, que los años transcurridos pueden hacerme ver lo no visto antes - experiencia bien conocida de las relecturas-; concretamente, el interés por la poética, más vivo que nunca últimamente, por los trabajos en que ando metido. Con todo, ¿cómo no sorprenderme de sorpren- 
derme ahora encontrando que este libro es, no sólo el fruto del existencialismo en lengua española de que tengo noticia, sino uno de los más grandes de la filosofia, a secas, en nuestra lengua, de que también tengo noticia? Desborda, efectivamente, por todas partes, la poética: la comprensión de la poesía por comparación con los "sectores de la cultura" más relacionados con ella - como únicamente pueden comprenderse estas creaciones del hombre--, le hizo a usted articular toda una filosofía. Y una filosofía original en proporción suficiente para poder tenerla por suya. A estas alturas de la historia y alturas historicistas no hay quien piense sin "levantar", en el sentido del aufheben hegeliano, toda una masa de pensamientos de pensadores anteriores. Pero por mucho que deba su filosofía de la religión digamos a un Otto, o su filosofia del hombre, que es la fundamental y general de toda la suya, a Heidegger, aún en estas mismas secciones, y no sólo en las de poética, la suerte de que revive y recrea personal, auténticamente, todo, más lo que añade de su propia experiencia y reflexión sobre ella, bastan y sobran para dar al conjunto aquella proporción de originalidad. Celebro la preferencia que usted le dio sobre el resto del existencialismo, con acierto bien superior al de los restantes mexicanos influidos por el existencialismo en paso decisivo de la vida intelectual de ellos - pero es la forma en que usted lo repensó lo que me tiene sobremanera suspenso y es lo que me hace comprender la dedicatoria del ejemplar: AJ.G., a quien tanto debe este libro. Sin embargo, tengo que decirle - y me alegro de tener que decírselo, porque le probará que no le estoy haciendo tan sólo elogios amistosamente convencionales-que en este punto me impone su libro un par de reparos metodológicos importantes. Entre la poética más especificada, la concepción de la poesía es parte de la concepción general del libro, y no sólo esta concepción, encuentro un poco de demasiada distancia. Lo que me parece provino de aplicar a la poesía una concepción venida para usted de fuera de ella - aunque pudiera haber venido de la poesía para Heidegger, lo que no me parece ser el caso, pues Ser y' tiempo me parece independiente, por anterior, a la versión filosófica de Heidegger hacia la poesía-, en vez de sacar de la poesía la concepción como autóctona de ella, de la poesía. 
Pero no sólo el filósofo de esta obra me tiene admirado. Tanto, por lo menos, me tiene así también el historiador de la literatura, de las ideas. Las partes, los capítulos de tal contenido son literalmente estupendos, de novedad y profundidad.

En fin, hasta la posición política que la obra toma es aquella que he creido deber tomar si no me engaño mucho.

Con El arco r la Lira y El Laberinto de la Soledad que siempre me ha parecido el mejor libro sobre su tema, lo que para mí es decir mucho - debía usted ser contado, por descontado, en la primera línea de la filosofía, no solamente mexicana, sino de lengua española. $Y$ es ingrediente principal de la sorpresa antes mentada el encontrarme, no con no saberle o recordado contado así públicamente por nadie, sino con no haberlo contado así públicamente en alguna ocasión yo mismo, que me he ocupado como lo he hecho con la filosofía de nuestra lengua en general y la mexicana contemporánea tan en especial. Es deuda que pagaré aún.

Ahora quisiera aprovechar el resto de esta carta, que empieza a rebasar los límites de la extensión propia del género, para pagar otra: la contraída por su carta de 25 de julio ¡de 1961!, que ha aguardado, paciente, sobre mi mesa hasta este día de hoy la respuesta. Compréndame y perdóneme el retraso de esta carta amigo Paz. No sé cómo me las arreglo, pero lo cierto es que estoy continuamente abrumado de trabajos y urgentes. O sí sé cómo me las -desarreglo: no sé decir no a los muchos, amigos, gentes e instituciones a quienes debo atenciones, honores, servicios, y que me piden cursos, artículos, conferencias, todavía traducciones, y otras cosas, prácticamente sin intermitencia y casi todas a plazo fijo, las más de las veces perentorio. Este año ha sido el del Congreso de filosofia aquí: usted se figura lo que ha requerido de los pocos que había aquí para organizarlo. Ha sido también el de un curso de Etica, materia de que no había dado cursos desde - España: usted se figura lo que ha requerido el prepararlo, habiéndome pedido que lo dicte no más de una quincena antes de empezar las clases del año académico. Y debió haber sido el de una segunda visita a la Universidad de Puerto Rico, aplazada para el 64, como el 62 fue el de una primera visita a la misma Universidad. ...Así que, de cuando en cuando, al aca- 
barse una temporada de gran trabajo, antes de meterme a otra, por necesidad biológica de descanso, me tomo uno de semana, de quincena a lo sumo, que aprovecho para cosas como ésta para la que aprovecho estos dias que me estoy tomando despues del Congreso, antes de meterme en la preparación de los cursos de Puerto Rico: escribirle a usted esta carta.

Al llegar aquí, tuve que interrumpir la carta para atender a cosas más urgentes que inopinadamente me cayeron encima - y la interrupción ha durado casi un mes: el Rector Chávez, que se ha propuesto poner orden en cuanto andaba sin él en la Universidad, ha dispuesto, entre otras muchas cosas, que se regule, en plazos perentorios, la situación del profesorado-y nos cayeron encima los concursos para provisión de plazas a los miembros de las comisiones y jurados dictaminadores -y la de los pasantes - y nos cayeron encima las tesis, por millares en la Universidad, por decenas en Filosofía y Letras. Los exámenes de tesis de cuyos Jurados soy sinodal no han acabado aún; pero las comisiones y jurados de que soy miembro acaban de acabar su tarea, y ello juntamente con el final de las clases y seminarios - aunque quedan los exámenes- acaba también, de darme un respiro.

En su carta hay una serie de puntos que requieren contestación por mi parte - al cabo de dos años y medio como a raiz de la carta: actualidad persistente de los temas de nuestro interés que me da una gran satisfacción, como me figuro que se la dará a usted.

Me hace usted ciertas preguntas y una incitación y dice usted algo que me tiene singularmente suspenso y admirado.

A mi me parece que no va a haber sustitutivo para la netafísica. Que todo lo que va a seguir habiendo, es:

las disciplinas filosóficas no metafísicas, desde la Lógica, matemática, hasta las que se ocupan con el hombre y entre las cuales y las ciencias que les corresponden hay tan poca solución de continuidad, que parecen reducirse a éstas: filosofía social y sociología, filosofía y ciencia de la religión, filosofía y ciencia del arte...;

la filosofía de la Metafísica, parte de la Filosofía de la Filosofía, o de la reflexión de la Filosofía sobre sí misma, como reflexiona sobre los otros sectores de la cultura, en la Filosofía 
de la Ciencia, del Arte, de la Religión...,y que parece compartir el destino de éstas indicado en la parte anterior: la Metafísica puede ser un producto arcaico ya de la cultura, como otros, tan susceptible como éstos de ser estudiado indefinidamente, histórica, teórica, críticamente, por el mismo valor de todos en definitiva antropológico, de conocimiento del hombre, de su pasado, de su naturaleza;

la religión o el residuo de ella que debe pensar inextinguible quien precisamente reconoce los límites de la razón pura o teórica: de este reconocimiento es correlativo al del misterio del mundo para el hombre, particularmente el del puesto del hombre en un mundo tan in-humano fuera del hombre mismo: el gran misterio del hombre para sí mismo que es constitutivo esencial de su propia naturaleza humana... Si "Dios" es, pues, un nombre más apropiado aún para el misterio mismo que para toda presunta revelación del misterio o extinción de éste, Dios no ha muerto, ni morirá, mientras esté vivo el hombre, es decir, mientras éste no muera como especie o no evolucione a otra, si es previsible, posible tal evolución - de la que no parece haber el menor indicio.

Si la verdadera filosofía y poesía son a estas alturas la filosofia de la filosofia y la poesía de la poesía, en todo caso no habría que confundir la poesia de la poesía y la filosofia de la poesía: la filosofía de la filosofía y la filosofía de la poesía son filosofía - como es filosofía de la poesía El arco y' la lira; la poesía de la poesía es poesía - como es poesía de la poesía.

Lo digo contra confusiones, no ciertamente de $V$., pero sí más difundidas de lo conveniente.

La incitación que me hace, es a escribir una obra que caracteriza desinteresadamente asi: [...]

Pero, vamos a ver, mi querido y admirado Octavio Paz: ¿No se trata de una obra que a usted le gustaría ver escrita - por usted?; ¿Será V. excepción a la regla de que las obras que se propone a otros escribir, son obras que quienes las proponen quisieran escribir, más consciente, más inconscientemente, más decidida, más veleidosamente? En todo caso, y a pesar de su incitación de V., no puedo ya hacer entrar nada semejante en mis planes, porque aún reducidos a éstos simplemente a publicar lo que tengo escrito e inédito, me temo no disponer 
de tiempo, de vida, para llevarlos a cabo. No ambiciono nuevas empresas. Me daría por archisatisfecho con haber salvado el material acumulado a lo largo de la vida hasta ahora, dándole forma definitivamente publicable.

Le reproduzco el pasaje que me tiene suspenso y admirado - porque proyecta una luz de mediodía esplendoroso sobre una peculiaridad de toda la cultura actual que había visto sólo parcial y oscuramente hasta ahora. [...]

Aquí tuve que dejar otra vez la carta. Y hoy, 12 de diciembre, que vuelvo a ella, en Guadalajara, donde estoy dando un curso intensivo - dos horas diarias, de lunes a sábado, ambos inclusive, durante dos semanas, lo que da casi tantas horas como un curso semestral corriente de la Facultad en México: que tiene que prestarnos, a sus profesores, a los de provincias, faltas de bastantes para poder cubrir los planes de estudios-, decido darla por terminada y remitírsela, sin más espera, no sea que ésta sea eterna. Aprovechando la cercanía de la Navidad y el Año Nuevo para deseárselos felices.

A José Gaos gran amigo a quien veo muy poco pero le quiero siempre. Le mando a Ud. este mi último libro por una discípula, Fernanda Navarro, ella le lleva también un abrazo de León Felipe.

Méx. Enero 1966

Querido León, Fernanda Navarro me entregó el ejemplar de su Violín ayer por la tarde. Por la noche empecé a oírlo, y no pude dejar de hacerlo ni dormir antes de acabarle. Si no es la manera de leer poesía, tampoco pude hacer otra cosa.

La lectura fue resultándome tan emocionante, que en más de un paso se me hubieran soltado las lágrimas, si los hábitos profesionales no me hubiesen hecho presente a tiempo que la actitud estética no consiste en dejarse poseer por las emociones promovidas por las obras de arte, sino en inhibirlas para apreciar los valores objetivamente realizados en ellas -y así fui a costa de los sentimientos, apreciando por ejemplo, y al azar del recuerdo, la Cruz vacía que puede tocarle hoy a sualquiera, la inexistencia de la Nada si existe el infierno, el juego de prestidigitación de que podría salir el hermano de 
Jesucristo, el regalo de las últimas palabras hijas de su imaginación, la petición de una cosa sencilla al carpintero, y tantas otras ideas poéticas originales, sorprendentes, impresionantesemocionantes; y tantas otras bellezas, de imagen, de expresión. Pero cuando llegué a releer "Piedra aventurera", empecé a sentir que no lograba continuar en la misma actitud, y cuando acabé de releer "...Para cada hombre guarda... un camino virgen Dios", dejé de lograrlo, resueltamente, irreprimiblemente; y así, hasta el final, de aquella misma primera piedra aventurera, que dando la vuelta en la honda de medio siglo, acaba de salir por la tangente a dar justo, justo en la frente misma de Goliat.

No se necesita llegar a los ochenta, basta haber pasado de los sesenta, para que le dé a uno lo mismo que le tengan por tal o cual, y a mí me da lo mismo que me tengan por mal español, por mal patriota, si declaro que desde que arribé a México no sentí nunca la nostalgia de España, que, en definitiva, me siento más a gusto en la Nueva que me sentía en la vieja, y hasta que quiero más a mi patria de destino que a la de origen. Pero al releer "Piedra aventurera" y "Nadie fue ayer", se me representaron en la imaginación el ejemplar del librito Versos y" oraciones de caminante, el artículo de Canedo en España, mis diecisiete o dieciocho años, la España de aquellos años, tan vivamente - aunque las imágenes ya no fuesen de una fiel imaginación reproductora, menoscabada por el transcurso del medio siglo, sino de una imaginación creadora de recuerdos alterados-, que he sentido lo que no habia sentido en ningún momento de los veintisiete años y pico que llevo ya en México. Obras de la poesía. De la poesía, sí. Porque no sé si Octavio Paz dirá de Ese viejo y roto violín lo que dijo de Ganarás la luz, aunque me figuro que lo dirá; pero a pesar de su autoridad de poeta universalmente reconocido y de teórico de la poesía, si no tan universalmente reconocido, para mi tan bueno como poeta, si no es que mejor, para mí es la poesía de $\mathrm{V}$. poesía, gran poesía, alta y honda poesía. Pues ¿por qué no lo sería? ¿Por la forma que V. mismo caracteriza en este libro como versículos expresivos del ritmo mismo de la vida de su alma, como no podría hacerlo más perfectamente el mejor cultivador de la Ciencia de la Literatura? Me parece que no; ni tampoco 
por el fondo, de ideas e imágenes, escenas y diálogos que las incorporan; sino por no haber entre el fondo y la expresión las relaciones, o la falta de relaciones, que hay en la poesía más vigente, o quizá simplemente más reciente de origen, y le dan el hermetismo que le faita a la de V.; que pueden reducirse a la supresión de las referencias a los objetos que hacen posible comprender de qué se habla, y de las relaciones entre los objetos y las lógicas entre las ideas que hacen posible comprender qué se piensa de las cosas, y que practicado todo ello como se practica ya, mecánicamente, da por resultado una poesía "prefabricada", como me dijo el poeta puertorriqueño Josemilio González, reconociendo la justeza de observaciones que le hice sobre uno de sus libros. Si éste su último libro fuese rigurosamente contemporáneo de los Versos y Oraciones, parecería tan de poesía, y tan de buena poesía, como pareció en su día su primer libro. ¿Se llegará a sostener que el mero "anacronismo" o "asincronismo" de una obra de arte basta para impedir la valía estética?... Lástima no poder vivir para ver si lo que queda en la historia es más lo que siguió cada paso de ella o lo que resulte haberlo dado...

Cierto que hace mucho que no nos vemos. $Y$ es que no sólo el viejo poeta del roto violín, sino también otros, no somos cada uno más que un gusanito ciego que camina en la sombra "del rincón de la ciudad enorme, disforme, anormal, en el que hace su vida, tocando un instrumento más o menos roto. Pero cierto también que, a pesar de ello, le quiero siempre, asimismo, y le admiro de todas veras y le deseo muchos años de vida aún -y esto último no sólo como piadoso deseo. Hay en la vida varias crisis: unas muy conocidas y reconocidas por todos, otras no tanto, quizá porque tampoco tantos llegan a ellas: crisis en la adolescencia, crisis en la madurez, crisis de la andropausia o entrada en la vejez, y también crisis de la vejez misma; y quien supera una, como que se asegura el tramo de vida siguiente hasta la siguiente crisis. A mi me parece que $\mathrm{V}$. ha pasado en estos años pasados por la crisis de la vejez misma, pero que dichosamente la ha superado, y que por ello se ha asegurado V. el tramo de la vida que se extiende hasta el centenario. Amén.

Un afectuosísimo abrazo de su 
Universidad Nacional Autónoma de México I de mayo de 1966

Sr. Dr. Leopoldo Zea,

Director en funciones de la Facultad de Filosofía y Letras

Mi querido Zea:

Yo, que por no poder ser nunca tan plenamente mexicano como si hubiera nacido en México, he pensado siempre que no debo tomar en la vida pública del país más parte que la escuela del cumplimiento de los deberes ciudadanos también del mexicano sólo por naturalización, en cambio pienso que los nombramientos de doctor honoris causa y profesor emérito con que me ha honrado la Universidad no sólo me autorizan, sino que me fuerzan a considerarme universitario tan plenamente como para obligarme en conciencia a proceder en esta Universidad como procediera en la de mi país natal, si no hubiera debido "trasterrarme" de él a éste. Por eso creo que puedo y debo decir a V. que estoy estupefacto de ver que el gran número de universitarios que han manifestado públicamente su reprobación, condenación, repulsa, de los mayores atentados posibles contra la disciplina universitaria, las normas, no por no escritas menos vigentes, de la convivencia académica $y$, aún civilizada, y el que venía siendo espíritu de la Universidad, parecen haberse contentado con ello y estar dispuestos o resignados a seguir conviviendo en la Universidad con los autores de tales atentados, en vez de declararse incompatibles con éstos y de dar al Poder Público la posibilidad de optar entre ellos y los autores de los atentados para continuar integrando la Universidad. lo que sería la más decisiva admonición y la más segura prevención contra la perpetración de actos semejantes en el futuro. He dicho "al Poder Público". porque estimo que la iniciativa de ello correspondía a la $\mathrm{H}$. Junta de Gobierno de la Universidad, en vez de haber aceptado recibir, iy sólo simbólicamente!, una pequeña parte de los locales universitarios, que es reconocer con los hechos. aunque no lo sea con las palabras, que actuará en ellos cercada y condicionada por los autores mismos de los atentados. La segura objeción de la salvación de la autonomía universitaria. 
no me convence: pues la autonomía universitaria es la obligación - aunque al pronto suene paradójico-impuesta estatutariamente a la universidad por el Estado mexicano, que es un Estado constitucionalmente liberal, de funcionar con arreglo a los principios de libertad de cátedra, investigación y expresión, con la consiguiente autolimitación que se impone el Estado, de abstenerse de intervenir en tal funcionamiento; pero en modo alguno es la imposibilidad legal para el Poder Público de prestar a la Universidad, cuando la prudencia política se lo aconseje, la fuerza material de que ella carece, justamente para asegurarle o devolverle las condiciones de su funcionamiento con arreglo a tales principios. En todo caso, me siento universitariamente incompatible con los autores de los atentados hasta el punto de no sentirme con fuerzas morales para seguir en la Universidad cuando en ésta permanecen ellos, por lo que, debido más a los tuétanos de que precisamente este sea el final de mi carrera universitaria, presento a $\mathrm{V}$. mi renuncia como profesor, rogándole se sirva darle el curso debido.

Me despido, pues, de V., querido Zea, como Director de la Facultad, con el viejo, admirativo y entrañable afecto, ahora conturbado y entristecido, que sabe le tengo.

México, D.F., 18 de mayo de 1966

Sr. Dr. Leopoldo Zea,

Director de la Facultad de Filosofía y Letras

de la Universidad Nacional Autónoma de México

\section{Querido Zea:}

Me ha dicho V. de palabra que las autoridades universitarias a las que participó $\mathrm{V}$. mi renuncia no quieren aceptarla, lo que equivale a pedirme que la retire, a lo que estoy dispuesto si me da $V$. en nombre de dichas autoridades las razones que tengan para hacerme tal petición, y que por lo pronto no se me alcanza que pueden ser otras que la de la falta de fundamento de las dos razones en que fundé la renuncia.

La primera, los hechos que tuvieron lugar en la Rectoria el 26 de abril pasado, según los testimonios dados de ellos por 
la prensa, únicos que conozco, singularmente el del Sr. Haro, y la calificación que me merecieron, de "los mayores atentados posibles contra la disciplina universitaria, las normas, no por no escritas menos vigentes, de la convivencia académica $y$, aún, civilizada y el que venía siendo espíritu de la Universidad." Si V. puede asegurarme que tales hechos no tuvieron lugar como atestiguó singularmente el Sr. Haro, a pesar de no haber sido desmentidos públicamente por nadie, ni siquiera los acusados, que yo sepa, o que fueron menos graves, o que, habiendo tenido lugar como el dice, concurren en ellos circunstancias atenuantes o hasta eximientes, es claro que se anularía la primera y fundamental razón que he tenido para presentar la renuncia y que deberia retirarla.

Pero aun aceptando los hechos y la calificación que me merecieron, puede considerarse inválida mi otra razón: el no sentirme con fuerzas morales para seguir en la Universidad cuando permanecen en ella los autores de los hechos. Puede pensarse, en efecto, que, aceptando tal, los autores de los hechos, se han deshonrado como universitarios, y que compartirá su deshonra la Universidad si no los sanciona justamente o no los obliga, al menos, a retractarse pública y solemnemente, y no ofrece siquiera la reparación moral de semejante sanción o retractación a quien era, a pesar de todo, en el momento de los hechos todavía su legítimo Rector; $\mathrm{y}$, recordando el "nobleza obliga", que el más honrado por la Universidad $-\mathrm{y}$ lamento no saber de otro que, no habiendo nacido en México, lo haya sido con el doctorado y el emérito-es el más obligado a hacer por su honra; y que el aband ono de la Universidad no sería cumplir con esta obligación, sino un desagradecido, desleal, cobarde y egoísta desertar del cumplimiento de ella, el cual únicamente sería factible dentro de la Universidad, como el cooperar a su debido funcionamiento en general. Por todo lo cual, si así juzgase $V$., con las autoridades aludidas, a pesar de juzgar yo en parte lo contrário - que no puedo hacer por la honra de la Universidad nada más, ni nada que sea más, que dejarla ahora -, subordinaría mi juicio personal al colectivo de personalidades a cada una de las cuales estimo superior a mí y a todas juntas muchísimo más superiores que a mí, y también retiraría la renuncia. 
Y puesto que presenté la renuncia razonada formalmente por escrito, creo deber esperar que me pida V. el retiro de ella en la misma forma razonada y escrita, para poder retirarla efectivamente.

México, D.F. 7 de julio de 1966

Sr. Dr. José Gaos

Presente

Querido Maestro:

En primer lugar quiero pedir a usted disculpas por haber retardado mi respuesta a sus dos cartas de lo. y 19 de mayo de 1966, en las que me habla de su renuncia como Profesor Emérito de esta Facultad a mi cargo. El retardo tiene una explicación obvia, que usted conoce. En primer lugar, dar tiempo para que los acontecimientos que forzaron esa renuncia se aclarasen y desde luego para que usted, en función con los mismos, viese menos severamente la situación planteada en la Universidad.

Estoy desde luego de acuerdo con usted en que esos sucesos no deben ja más repetirse y que los universitarios debemos buscar la forma de que así sea. Los hechos de que usted me habla en una de sus cartas fueron, al parecer, tal y como los han escrito los que sufrieron los mismos. Estoy de acuerdo en toda la condenación que tanto usted como otros muchos universitarios hemos hecho. No tengo que ocultarle que yo mismo me he planteado la necesidad de tomar una medida semejante a la suya: sin embargo, pensándolo, y no es una justificación, he considerado que sería una solución, en mi opinión la más fácil y que resulta más efectiva la acción por mínima que sea dentro de la propia Universidad, y en eso, puede usted estar seguro que hemos estado apoyando una solución que resulte honrosa a nuestra Universidad. A usted no se le escapa que en esta crisis universitaria han jugado elementos extrauniversitarios que lesionan no sólo al orden universitario, sino al de la propia nación; elementos para los cuales nuestra Universidad, por su 
misma estructura legal carece de otra fuerza que no sea la moral, una fuerza que desgraciadamente no siempre resulta con la eficacia que fuera de desear.

La actitud tomada por usted me parece admirable y digna de todo respeto, aunque creo que llevada con demasiada severidad, al enjuiciar comparativamente al resto de autoridades, profesores y universitarios en general, que de tomar la misma actitud pondría simplemente fin a la Universidad, o cuando menos, la entregaría en manos ajenas a la misma.

Usted sabe, Maestro, que uno de los elementos de gran admiración por su persona y su obra en México, lo fue su clara decisión de "plantar sus tiendas" aquí, desde el mismo momento en que llegó a esta tierra considerándose no un desterrado, sino un transterrado. Esto es su decisión de acompañar a esta Nación, la Universidad y sus hijos en sus diversas vicisitudes, buenas unas, malas otras. Así lo entendió la Universidad, que se sintió honrada con su persona cuando, en forma unánime, lo declaró Doctor. Honoris Causa y Profesor Emérito; una forma de honrar a quien tanto la honraba.

Me dice usted que por ello se siente más obligado a tomar la actitud que me indica y que resulta ser precisamente la que la Universidad, o los universitarios, si usted quiere, no han querido tomar por razones que se semejan mucho a las que personalmente le he expuesto. Por este motivo yo le rogaría, no como Director de esta Facultad, ni como expresión de autoridad alguna, que reconsidere su renuncia y vuelva a "plantar sus tiendas" entre nosotros, siguiendo nuestra suerte que creo será, a pesar de todos los problemas, mejor, una vez capeada la crisis.

Debo decirle también que he hablado de su renuncia con el Sr. Rector de la Universidad, Ing. Javier Barros Sierra, quien se encuentra dispuesto a hablar con usted personalmente, plática que le he rogado aplace para que usted pueda ver, en función con la marcha de los acontecimientos, si mantiene su actitud.

También quiero decirle que su renuncia, precisamente por referirse a honores recibidos, ya que usted no es un profesor ordinario, no podría ser aceptada por ninguna autoridad salvo por la Universidad en pleno que le otorgó tal honor, esto 
es, el Consejo Universitario. En mi opinión, me disculpa que sea franco, no creo que se debia plantear esa situación ante el Consejo Universitario que implicaría el rechazo absoluto de un honor otorgado por esta Universidad y que creo no está en su ánimo hacer, sino simplemente presionar, como corresponde a un universitario como usted, para que sucesos como los que hemos conocido, no vuelvan a ser jamás repetidos.

Sé también que usted ya adquirió un compromiso con $\mathrm{El}$ Colegio de México. De esto hablé con su Presidente, Sr. Lic. Víctor Urquidi. Quiero decirle que ese compromiso no es en ninguna forma incompatible con su carácter de Profesor Emérito de esta Universidad, ya que el Estatuto de Profesores deja claramente expresado que el Profesor Emérito no posee ninguna de las obligaciones del profesor ordinario y sólo se le pide la colaboración que libremente tal profesor quiera dar a la Universidad.

Pasando a otro punto, simplemente para apoyar lo expuesto anteriormente, en caso de que no hubiese sido designado Profesor Emérito, hubiese usted entrado en la jubilación, la cual, aunque impide que el jubilado tenga ningún otro nombramiento dentro del Estado, incluyendo la Universidad, sí permite el contrato entre el jubilado y cualquier institución gubernamental que le permita el aprovechamiento de la persona que se encuentra en esa situación y pueda aún dar mayores rendimientos. Su caso, desde luego no es éste, sino el que ya le he señalado como Profesor Emérito, así que en ninguna torma tendría usted, en caso de retirar, como le ruego, una renuncia que no le puede ser aceptada, que renunciar al compromiso que usted adquirió y que podría realizar sin violación legal del orden universitario, como puede usted ver en el artículo 108 del Estatuto del Personal Docente al Servicio de la Universidad Nacional Autónoma de México.

En todo caso, si usted insistiese en no regresar a esta Universidad, mientras no se aclare la situación ya descrita, tampoco está usted obligado a dar curso alguno, cosa que desde luego no quisiera. Son estos precisamente privilegios del Profesor Emérito. Vuelvo a insistir sin embargo en que regrese con nosotros y nos ayude a lo que tratamos que sea la reestructuración de esta Facultad a mi cargo, y la Universidad en 
general, aprovechando precisamente la crisis que se ha planteado y que podríamos transformar en positiva.

Con el afecto de su discípulo.

Leopoldo Zea

(rúbrica)

Palabras del doctor Leopoldo Zea en la entrega de la Gran Cruz de Alfonso el Sabio el 18 de diciembre de 1984 en Madrid, España

$\mathrm{Z}^{\mathrm{N}}$ primer lugar mi gratitud al gobierno de España, y a las Einstituciones y personas que han hecho posible el honor que ahora recibo, la Gran Cruz de Alfonso X el Sabio. Esta condecoración, y el hecho que la reciba en esta Ciudad de Madrid, en el corazón de España, tiene para mí un especial, peculiar significado. Considero que este honor culmina y da sentido a la promesa que hiciera a mi nunca olvidado maestro José Gaos la mañana del 10 de junio de 1969 . La tarde de ese mismo día recibiría la amarga noticia de que el maestro había dejado este su transtierro en México para entrar a la historia común de México, España y Latinoamérica. El postrer encuentro aún lo tengo vivo en mi memoria. Lo recuerdo haciéndome algunas recomendaciones respecto a su obra y, a continuación, la pregunta: "¿Zea, usted ha estado varias veces en Europa, por qué no ha visitado España?" "Maestro -le contesté-, no lo he hecho por usted. Si usted no puede entrar allí yo no podré tampoco hacerlo". Con palabras cortantes, agregó: "Zea, eso es asunto mío, no suyo. Usted debe ir, y aquíle arranco la promesa de ir a España en la primera oportunidad que tenga. Allí está la otra raíz de la identidad de México y la América de la que es parte; la identidad que usted viene insistiendo en definir." La promesa fue hecha y cumplida dos años después: en 1971, hice mi primer visita a la España de mi maestro y mía. He vuelto muchas veces y en cada vuelta pude ver lo que a mi maestro hubiera gustado tanto ver, el cambio hacia la España de ahora por la que él había luchado en su momento.

En cada visita comprendí mejor el calificativo que Gaos había forjado, el de transtierro. Esto es, el de transitar por España 
como si fuera la propia tierra, como Gaos transitó por México y América, por tierra mexicana y latinoamericana como parte de la misma España. Aquí he encontrado otra raíz de la identidad buscada, raíz que ya sentía y presentía. La raíz de una peculiar identidad que por su diversidad resulta más rica y universal. Por ello, en este día, en el que recibo, aquí en España, este gran honor, honor relacionado con la España madre de la España actual y de la España al otro lado del Atlántico, siento que de esta forma culmina, alcanza su pleno sentido, la promesa hecha, el pleno enraizamiento de mi propia identidad con uno de sus orígenes.

Estamos ahora, precisamente, en España y América, preparándonos para conmemorar el Quinto Centenario del Descubrimiento de América. No importe cómo se le denomine, lo que es ineludible es el significado que pa ra nuestra historia y la historia universal tiene ese 12 de octubre de 1492. En esta fecha se inició la dolorosa gestación de un mundo auténticamente nuevo. Un mundo nuevo por estar enraizado en una nación del llamado viejo mundo y en las naciones al otro lado del Atlántico que hasta antes de esa fecha eran desconocidas porquienes con ellas se encontrarian. Considero que en la medida en que reflexionemos con hondura sobre este encuentro y su sentido, realizaremos el descubrimiento de la región hasta ayer más encubierta que descubierta. Descubrimiento de la misma España que aportó su identidad a la identidad encontrada.

Por algo españoles y americanos han estado preocupados, a lo largo de la historia que siguió a ese hecho histórico, por su peculiar, pero también común identidad. La inteligencia española, como la hispanoamericana han bregado por definir una identidad obviamente existente, pero que escapaba una y otra vez a su definición, obligados a realizar irracionales a mputaciones de ese su propio ser. ¿Somos americanos?, ¿somos europeos? Se pregunta en América, como en España se preguntan a su vez, ¿somos españoles?, ¿somos europeos? Como si algo sobráse o algo faltase. Siempre sobrando o faltando lo que ineludiblemente se tenía y se tiene. Interrogantes nacidos paradójicamente de una identidad extraordinariamente rica y que, por serlo, se distingue de ot ras identidades que no se rebasa ron a sí mismas. 
La afirmación, de que Europa termina en los Pirineos, y la africanidad de España antes del descubrimiento y su americanización después del mismo, fue vista como una negación siendo expresión de la identidad de una España capaz de enriquecersu propia identidad con otras identidades, capacidad para mestizarse racial y culturalmente como expresión de la más alta cualidad de lo humano. Universalización plena, auténtica, pero que prejuicios al uno y en otro lado del Atlántico presentaron como corrupción de esa misma y rica humanidad. En la América española se presenta como la más absurda de las alternativas: ¡civilización o barbarie! La civilización como lo otro, lo extraño a una identidad extraordinariamente rica y que por serlo, distinta de identidades más limitadas.

Habremos de llegara ese 12 de octubre de 1992 conscientes de la riqueza que poseemos. ¿Indios? Sí, pero también españoles. ¿Europeos? También, pero también españoles y americanos. Ambas cosas y por ello expresión de un peculiar y rico mund o en el que el hombre se agranda comprendiendo a otros hombres; un pueblo a otros pueblos. Por lo que se refiere a mi América, nuestra América que diría José Martí, somos ya conscientes de que somos fruto de una doble raiz. Hijos de una doble patria, la madre España y la madre América. La España de raíces de las que es expresión el rey que ha dado nombre al honor que a hora recibo, Alfonso Xel Sabio. Rey que dio unidad y sentido a una cultura, fruto a su vez de otros mestizajes, haciendo posible a la España de nuestros días. Raíces también nuestras en América. Madre patria de. la España nación y las naciones al otro lado del Atlántico. Y Madre de la España nación, fruto de esa cultura y en este sentido patria hermana de las naciones de esta nuestra América.

Es en este sentido que recojo una utopía, nuestra utopía, la de una nación de naciones, de patria de patrias, de naciones hermanas, y al otroladodel Atlántico. Una gran patria que vaya de los Pirineos a la región que en Aniérica se forma entre el Río Bravo y la Tierra de Fuego. Patria de patrias, nación de naciones, que puede ser el punto de partida del reconocimiento de una gran identidad que abarque al mundo entero, sin menoscabo de las múltiples expresiones de identidad que la forman. Relación así solidaria, de pares entre pares, de iguales 
entre iguales, por ser cada una peculiar, pero al mismo tiempo capaces de reconocerse en otras peculiaridades como expresiones de su propia identidad. 